\title{
Congenital Pseudarthrosis of Tibia- Treated Using Ilizarov Technique
}

\author{
Balkrishan Agarwal ${ }^{1}$, Ramesh Chand Jindal ${ }^{2}$, Manjeet Singh ${ }^{3}$, Harinder Singh Sandhu ${ }^{4}$, Rajeev Gupta ${ }^{5}$ \\ ${ }^{1}$ Department of Orthopaedics, Maharishi Markandeshwar (Deemed to be University), Mullana, Ambala, \\ Haryana, India. ${ }^{2}$ Department of Orthopaedics, Maharishi Markandeshwar (Deemed to be University), \\ Mullana, Ambala, Haryana, India. ${ }^{3}$ Department of Orthopaedics, Maharishi Markandeshwar (Deemed to \\ be University), Mullana, Ambala, Haryana, India. ${ }^{4}$ Department of Orthopaedics, Maharishi \\ Markandeshwar (Deemed to be University), Mullana, Ambala, Haryana, India. ${ }^{5}$ Department of \\ Orthopaedics, Maharishi Markandeshwar (Deemed to be University), Mullana, Ambala, Haryana, India.
}

\section{INTRODUCTION}

The diagnosis of congenital pseudarthrosis of the tibia (CPT) in pediatric age group is difficult (1), particularly if the patient had repeated trauma and was mismanaged.[2,3] The etiology of congenital pseudarthrosis is unknown. Mostly patient presents with neurofibromatosis.[4] Most of cases have defect on anterolateral angulation. Most effective treatment option for CPT is surgery. Surgical methods like Ilizarov technique, intramedullary fixation, and grafting [5] with combination of two or three types surgeries. However, Ilizarov ring fixation is the most effective treatment option. Every surgery should include correction of deformity, bone remodeling, limb lengthening, and complete removal of the lesion. Many patients developed deformity and degenerative arthritis of knee and ankle joints. Unfortunately, operation can't differ according to the nature of disease history and pathology.[1] As such cases should undergo Ilizarov ring fixation. Most common complication was refracture. Therefore, an effective, safe and practical treatment method that minimizes the residual challenges after healing and accomplishes the multiple goals of treatment is needed.

\section{PRESENTATION OF CASE}

An 8-year-old female patient come to our OPD of Department of Orthopaedics with CPT in lower end of right tibia (fig. $1 \mathrm{~A}, \mathrm{~B}$ ). The patient had an old history of fall while playing and was treated with below knee slab. After 3 months, the patient developed pain while walking and had swelling. X-ray examination of tibia revealed angular deformity with anterolateral bowing (fig. $2 \mathrm{~A}-\mathrm{C}$ ) which is a typical finding of CPT. It is usually associated with neurofibromatosis.
Corresponding Author:

Dr. Balkrishan Agarwal,

Department of Orthopaedics,

MMIMSR, Mullana,

Haryana, India.

E-mail: drbalkrishan122@gmail.com

DOI: $10.14260 / \mathrm{jemds} / 2020 / 129$

Financial or Other Competing Interests: None.

How to Cite This Article:

Agarwal B, Jindal RC, Singh $M$, et al. Congenital pseudarthrosis of tibia- treated using Ilizarov technique. J. Evolution Med. Dent. Sci. 2020;9(08):582-585, DOI: 10.14260/jemds/2020/129

Submission 19-12-2019,

Peer Review 31-01-2020,

Acceptance 06-02-2020,

Published 24-02-2020. 


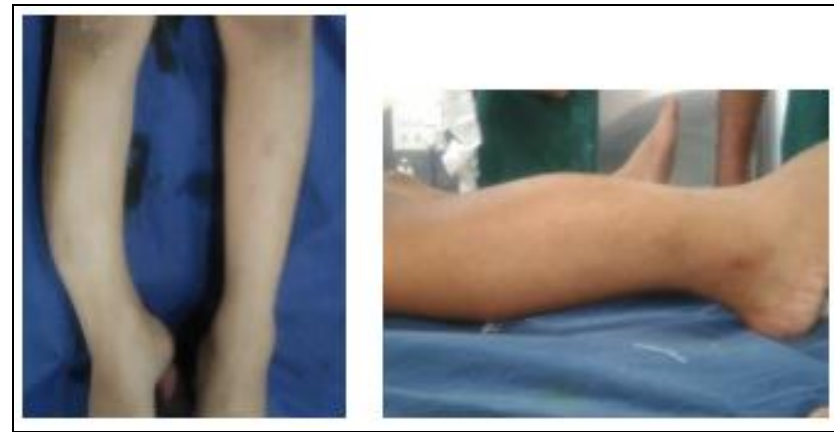

Figure 1. (A, B) Clinical Presentation at the Time of Admission

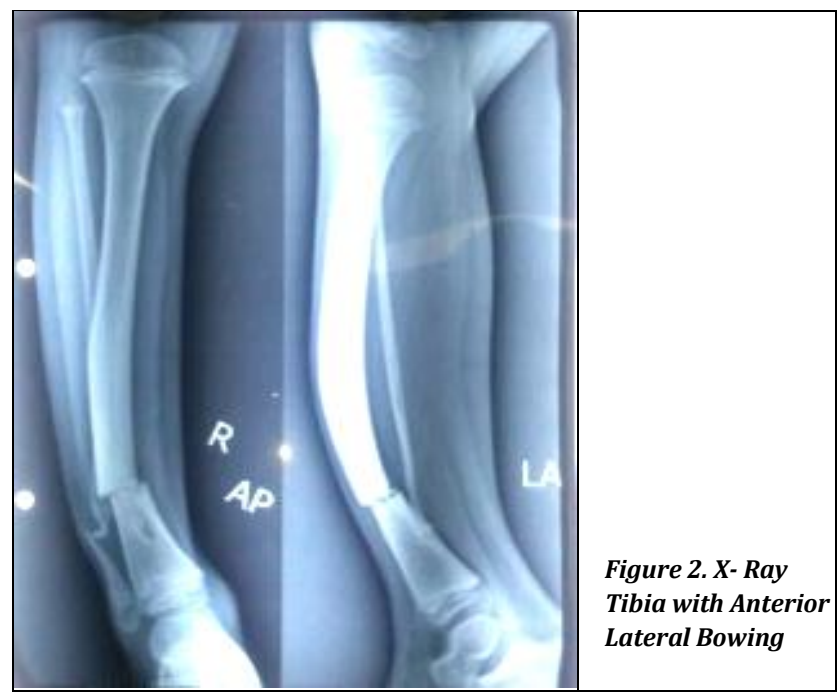

\section{Intraoperative Treatment}

The surgical incision was given over anterior aspect distal tibia and pseudarthrosis was exposed (fig. 3). Oblique osteotomy was done and sclerotic tibial parts (fig. $3 \mathrm{~A}$ ) were removed. At the same time, a longitudinal incision was made on the outside of the right lower leg exposing the fibula. A $2.5 \mathrm{~cm}$-long fibular graft was taken (fig. 3B) and inserted into medullary cavity of tibia after removing periosteum off the surface of fibula and external fixator was placed and checked with C-Arm image intensifier. Graft was taken from ilium and cancellous bone graft put in the defective part of tibia. Graft site was closed and aseptic dressing done (fig. 3D)

\section{Postoperative Treatment}

After operation, the force and deformity of the lower limbs were restored (fig. 4 A, B, C, D). Patient with external fixation started extending her affected limb after 1 week, and continued pressure was applied to maintain the stability of the force line. Knee and ankle were moved simultaneously to acquire strength and the space between the bones was increase by $1 \mathrm{~mm} /$ day. The rod was screwed 4 times a day at $90^{\circ}$ each time for the $1 / 4$ turn. The patient was followed up after 1-, 3- and 9-months. After removal of external fixator (fig. 6, $7 \mathrm{~A}, \mathrm{~B}$ ), the patient started partial weight-bearing after 3 months and gradually to full weight bearing on walking after 1 year and avoided heavy work for the near joints. After 1 year postoperatively, we found that the lower limb force line was normal, and lower limb shortening eliminated. The knee joint was not stiff, but ankle dorsiflexion was mildly limited. The patient started full weight-bearing walking without pain (fig. 7).
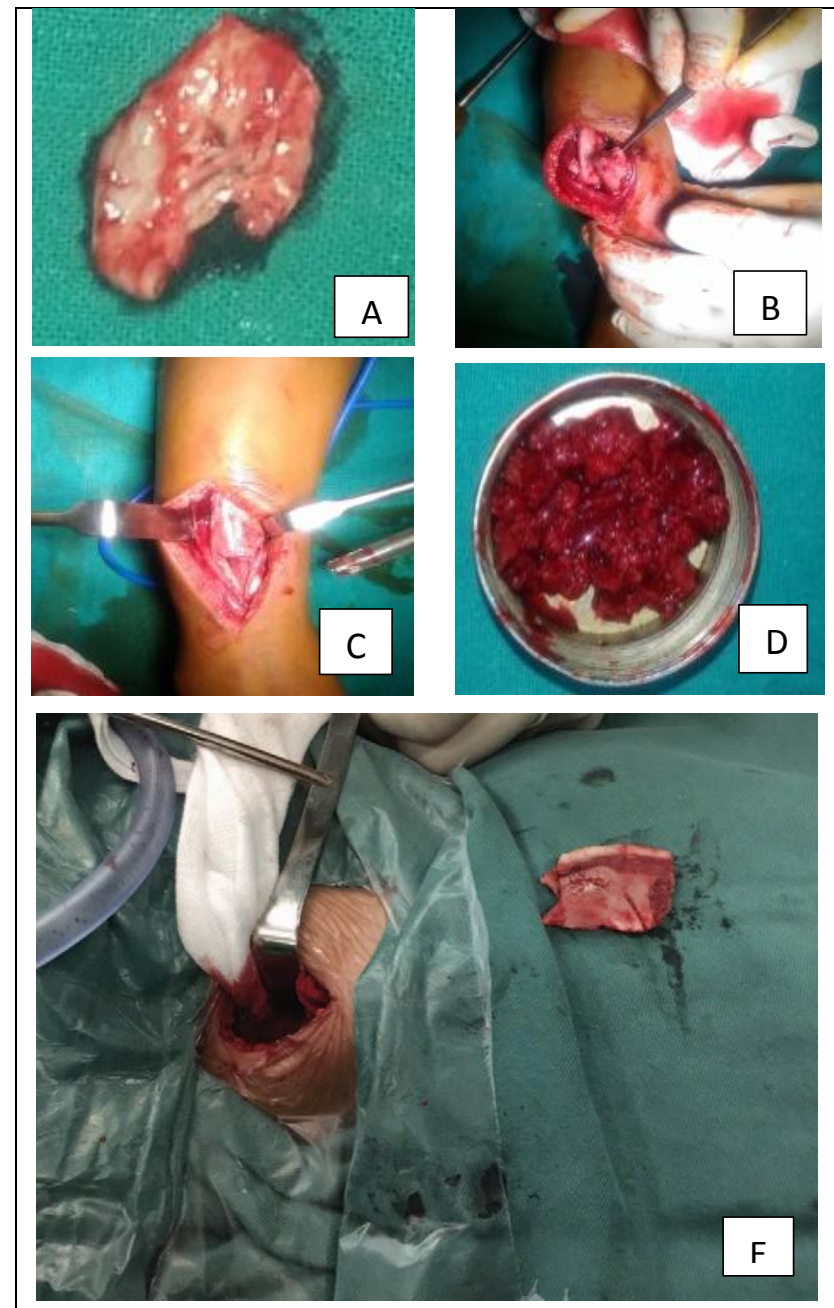

Figure $3(A, B, C, D, E)$. Resection of Lesion CPT of Tibia with Fibular and Ilium Graft Section
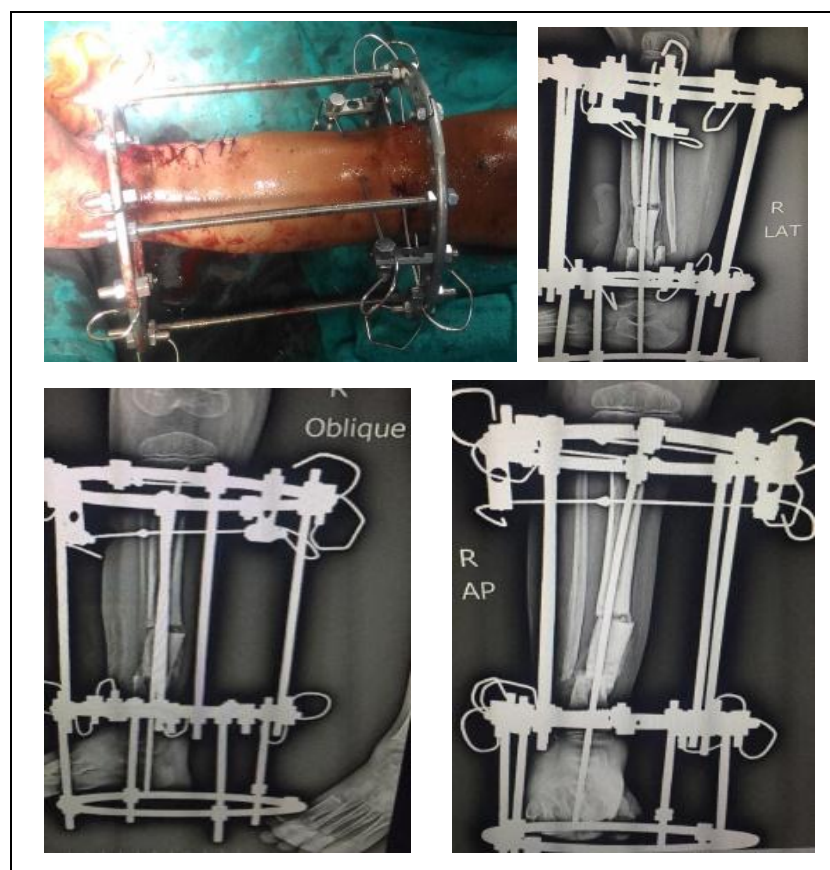

Figure $4(A, B, C, D)$. Closure Wound after Ilizarov Rim Fixation Post-Operative X-Ray after Ilizarov Fixation.

(AP, Oblique Lateral View) 

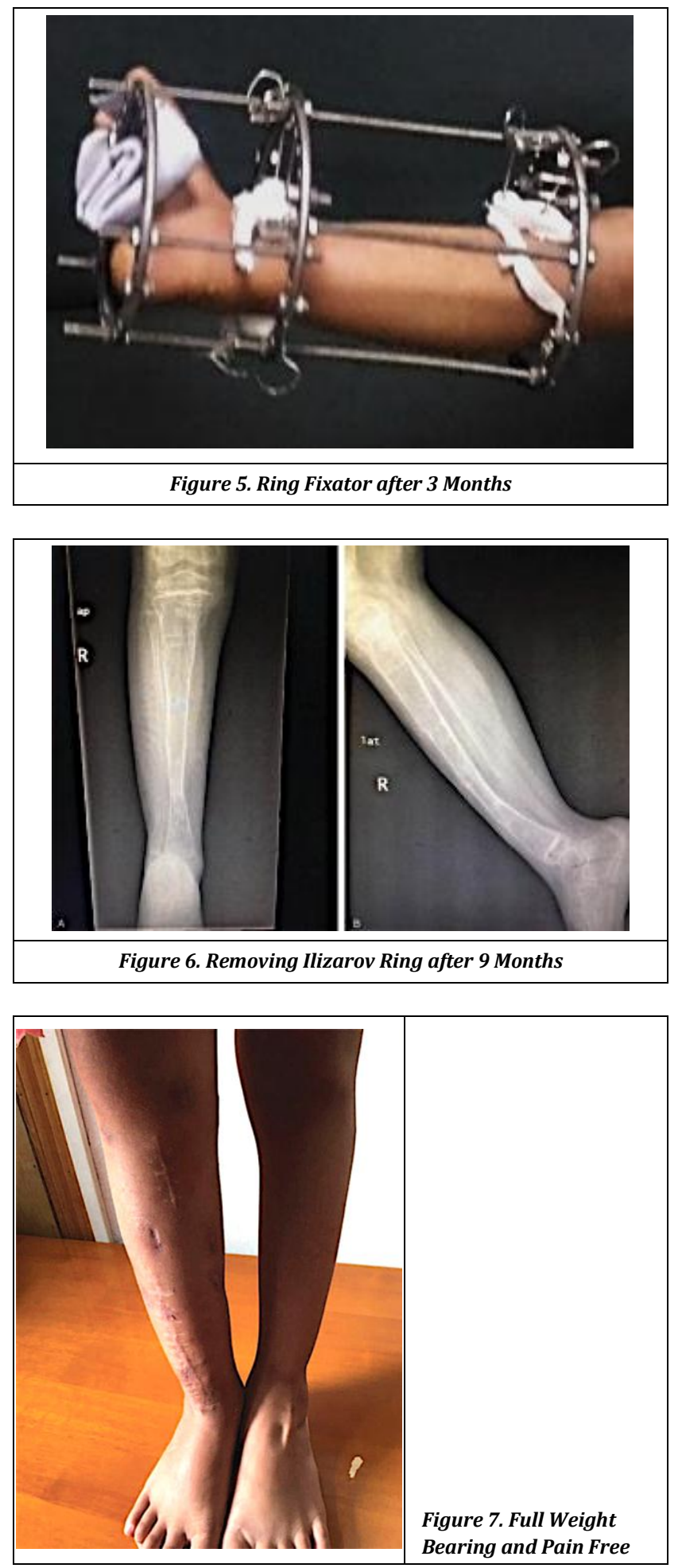

\section{DISCUSSION}

Achieving solid alignment and union in CPT is difficult for a surgeon to. ${ }^{[6,7]}$ In a study, Ohnishi et al opined that the most effective method for treating CPT was Ilizarov technique with graft [8] This technique did not provide solid union. Some studies state that the non-union of the fibula favours valgus deformities.[9,10] However, we have followed different surgical methods. In our patients, fibular graft was done and transported into tibia. The proximal and distal ends of fibula were not fixed, and the fibula is non-united ${ }^{11]}$. Therefore, cancellous bone graft was most useful for healing. Joints are stiff because of prolonged immobilization. It is thought that CPT usually is associated with anterolateral bowing. ${ }^{[9,12]}$ After healing the osteotomy, the limbs lengthened to the correct measurements. We corrected angulation and shortening deformity simultaneously in one sitting. We treated the condition with short hospitalization time and decreased hospitalization cost. The most common complication is refracture. The united bone provides inferior biologic and mechanical qualities, such as a tibial valgus, rotation deformity, small docking and sclerotic bone with no medullary cavity. Therefore a protective brace is recommended.[16,17]

\section{CONCLUSIONS}

Ilizarov method is safe, and effective treatment option for patients with CPT. We can achieve several goals like osteosynthesis, limb length lengthening, and ankle stabilization. Patient was stable after surgery. Patient was discharge on external fixator with reduced hospital stay and cost.

\section{REFERENCES}

[1] Ghanem I, Damsin JP, Carlioz H. Ilizarov technique in the treatment of congenital pseudarthrosis of the tibia. J Pediatr Orthop 1997;17(5):685-90.

[2] Joseph B, Mathew G. Management of congenital pseudarthrosis of the tibia by excision of the pseudarthrosis, onlay grafting and intra-medullary nailing. J Pediatr Orthop B 2000;9(1):16-23.

[3] Su YP, Wang MNH, Chang WN. Successful treatment of congenital pseudarthrosis of the tibia with long segment fibular allografting in a young child. J Formos Med Assoc 2007;106(3 Suppl) S44-9.

[4] Oetgen ME, Richards BS. Complications associated with the use of bone morphogenetic protein in pediatric patients. J Pediatr Orthop 2010;30(2):192-8.

[5] Vanderstappen J, Lammens J, Berger P, et al. Ilizarov bone transport as a treatment of congenital pseudarthrosis of the tibia: a long-term follow-up study. J Child Orthop 2015;9(4):319-24.

[6] Ippolito E, Corsi A, Grill F, et al. Pathology of bone lesions associated with congenital pseudarthrosis of the leg. J Pediatr Orthop B 2000;9(1):3-10.

[7] Kristiansen LP, Steen H, Terjesen T. Residual challenges after healing of congenital pseudarthrosis in the tibia. Clin Orthop Relat Res 2003;(414):228-37.

[8] Ohnishi I, Sato W, Matsuyama J, et al. Treatment of congenital pseudarthrosis of the tibia-a multicenter study in Japan. J Pediatr Orthop 2005;25(2):219-24.

[9] Shah H, Rousset M, Canavese F. Congenital pseudarthrosis of the tibia: management and complications. Indian J Orthop 2012;46(6):616-26.

[10] Mathieu L, Vialle R, Thevenin-Lemoine C, et al. Association of Ilizarov's technique and intramedullary rodding in the treatment of congenital pseudarthrosis of the tibia. J Child Orthop 2008;2(6):449-55. 
[1] Joseph B, Somaraju VVJ, Shetty SK. Management of congenital pseudarthrosis of the tibia in children under 3 years of age: effect of early surgery on union of the pseudarthrosis and growth of the limb. J Pediatr Orthop 2003;23(6):740-6.

[2] Bhowmick K, Varghese VD. retrograde intramedullary nailing for recurrent fracture in congenital pseudarthrosis of the tibia. J Foot Ankle Surg 2016;55(6):1287-91.

[3] Choi IH, Cho TJ, Moon HJ. Ilizarov treatment of congenital pseudarthrosis of the tibia: a multi-targeted approach using the Ilizarov technique. Clin Orthop Surg 2011;3(1):1-8.
[4] Pannier S. Congenital pseudarthrosis of the tibia. Orthop Traumatol Surg Res 2011;97(7):750-61.

[5] Tudisco C, Bollini G, Dungl P, et al. Functional results at the end of skeletal growth in 30 patients affected by congenital pseudarthrosis of the tibia. J Pediatr Orthop B 2000;9(2):94-102.

[6] Cho TJ, Choi IH, Lee SM, et al. Refracture after Ilizarov osteosynthesis in atrophic-type congenital pseudarthrosis of the tibia. J Bone Joint Surg $\mathrm{Br}$ 2008;90(4):488-93.

[7] Romanus B, Bollini G, Dungl P, et al. Free vascular fibular transfer in congenital pseudoarthrosis of the tibia: results of the EPOS multicenter study. J Pediatr Orthop B 2000;9(2):90-3. 